\title{
The Shaping of EU Competition Law \\ Pablo Ibáñez Colomo
}

Reviewed by Miguel Mota Delgado*

\section{Introduction}

The substantive evolution of EU competition law is characterised by numerous instances of inconsistencies. An analysis of the substantive impact of the institutional features of the EU competition law system contributes to explain some of these peculiarities. This is the main argument developed by Pablo Ibáñez Colomo in The Shaping of EU Competition Law, an empirically-driven work in which the Author succeeds in providing convincing explanations to some of the discipline's idiosyncrasies.

In the book, the Author provides an extensive analysis of both the caselaw and the administrative practice related to the interpretation of three key notions of EU competition law, considering first the institutional context in which each notion has been fleshed out and second the evolution in the interpretation of each notion in light of the behaviour of the European Commission (hereinafter the "Commission") and of the EU courts.

This choice of methodology contributes to make this work an innovative and original input to the discipline's literature, presenting new perspectives on the EU competition law system as a whole and offering food for thought on future discussions about the institutional structure sustaining this field of EU law.

\footnotetext{
* Junior Lawyer at Morais Leitão. Research Assistant at the Lisbon Centre for Research in Public Law of the Faculty of Law of the University of Lisbon. LL.M. College of Europe, Bruges. miguel.motadelgado@coleurope.eu.
} 


\section{Book chapters}

The book is divided into 3 parts (Theory, Analysis and Implications) and 7 chapters. In Part I, the Author introduces the research topic and establishes an analytical framework for the study of the EU competition law system. In Part II, the Author conducts an analysis of some key notions of substantive EU competition law, and, finally, in Part III, before concluding the study, the Author considers the implications of the analysis for the understanding of the substantive development of EU competition law.

In the first (introductory) chapter, the Author draws out his research topic, hinting as to how the patterns of behaviour of the Commission and the EU courts might influence the evolution of the interpretation of certain provisions of EU competition law. To understand such developments, it is necessary to consider how the Commission shapes its interpretation of said provisions and how EU courts engage (if the procedural framework enables it) with the choices made by that administrative authority. The Author promises to carry out (and essentially delivers) this analysis in an agnostic fashion, without any normative claims on the direction in which EU competition law or policy should develop.

Three fundamental notions which define the boundaries of the relative provisions are chosen as case studies for this inquiry: the notion of restriction of competition within the meaning of Article 101(1) TFEU, the notion of abuse under Article 102 TFEU and the substantive criterion against which mergers are assessed. A comprehensive approach covering a meaningful universe of cases is deemed necessary to draw reasoned conclusions and contributes to make this work an empirically-driven one, solidly established on extensive data.

The second chapter sets out a specific analytical framework for the study of the EU competition law system. As the Author explains, this field of EU Law is built on top of open-textured concepts, a feature enabling the occurrence of inconsistencies in the interpretation of some of its most central provisions and creating challenges for its administrability as well. "Static" inconsistency, unlike "dynamic (or intertemporal)" inconsistency, is not the somewhat inevitable (and to an extent desirable) by-product of an ever-evolving field of law, but a permanent issue, sometimes revealing itself across provisions, determining different results for similar factual situations. If one considers rebates, for instance, it may seem strange how standardised rebates and target rebates are treated differently by EU courts. As noticed by the Author later in the book, "the difference between 
these schemes is not one of principle, but of degree", raising the question as to why EU courts have developed two distinct analytical frameworks for this type of practice.

As the Author points out, it is not only important to determine whether inconsistencies exist, but whether there are factors contributing to the development and the perpetuation of such inconsistencies. Prosecutorial bias and judicial deference may sustain inconsistencies since the erratic action of the biased administrative authority will not be subject to sufficient judicial review. Claims of prosecutorial bias and judicial deference are accordingly at the centre of the discussion on the interplay between the institutional and substantive dimensions of EU competition law and will be successfully tested throughout the study.

The third chapter, the first of Part II, examines the notion of restriction of competition within the meaning of Article 101(1) TFEU. The elusive concepts of "by object" and "by effect" restrictions are at the heart of this analysis, where the Author, after considering the institutional context underpinning this provision, carries out an analysis of different types of Article 101(1) TFEU cases. Empirical findings reveal important insights on the substantive evolution of this provision. It becomes clear, for instance, how the substantive content of Article 101(1) TFEU was essentially shaped by the Court in preliminary ruling proceedings. Indeed, core Article 101(1) TFEU principles were defined very early on in cases such as Société Technique Minière, pre-empting the Commission's creativity. Moreover, far more cases concerning the notion of restriction of competition came before the Luxembourg judges via Article 267 TFEU than through Article 263 TFEU.

Further in the analysis, it is explained how post-Regulation 1/2003 "by effect" cases became a rarity, something explained by a conscious option of the Commission in privileging (easier) "fact-intensive" cases combined with a frequent use of commitment decisions. In the context of Article 101(1) TFEU, "fact-intensive" cases are cases where the legal framing as a "by object" restriction is relatively uncontested. The data gathered and processed by the Author shows that cartel cases represent 85 per cent of the decisions adopted in this period, where the majority of the other 15 per cent relate to clear-cut infringements, Cartes Bancaires standing as the most noticeable exception. Commitment decisions, on the other hand, became an intuitive solution for the Commission in (harder) "law-intensive" cases where the legal framing is less clear and recourse to informal 
and/or negotiated solutions becomes a desirable outcome. Indeed, as the Author points out, if we consider vertical restraints, "law-intensive" practices par excellence, it is perceivable how these conducts have been essentially dealt with through soft law instruments such as guidelines.

The fourth chapter considers the notion of abuse within the meaning of Article 102 TFEU, the second concept analysed in Part II. Following the same methodology as in the previous chapter, the Author finds that, unlike Article 101(1) TFEU, the substantive tone of Article 102 TFEU was set by the Commission essentially in the context of annulment proceedings. Statistically, Article 102 TFEU prohibition decisions are prone to be challenged in annulment proceedings, with 73 per cent of them following the route of Article 263 TFEU. This is not surprising considering how Article 102 TFEU practices hardly constitute clear-cut "fact-intensive" infringements. Furthermore, until Regulation 1/2003, the Commission was limited, at least formally, in its enforcement options, trapped in a twofold choice between prohibiting the practice and closing the file, a factor which contributed to a higher proportion of annulment proceedings.

The central role of the Commission in annulment proceedings resulted in noticeable substantive implications, namely considering what the Author dubbed as the "gravity effect" of the Commission's presence for the interpretative results of EU courts. Very interestingly, this explains, for instance, why Article 102 TFEU cases such as predatory pricing, exclusive dealing and "margin squeeze" cases were originally framed as "fact-intensive" ones, subject to reduced evidentiary standards and founded on relatively thin legal analysis. This did not mean however that the Commission succeeded in pushing forward expansive interpretations of Article 102 TFEU in each of its attempts. Indeed, as explained by the Author, if we consider predatory pricing, it is possible to notice that while in its decision in AKZO the Commission did not focus on the anti-competitive effects of that practice, the Court raised the substantive threshold, demanding some evidence of the capability of the conduct in driving equally efficient competitors out of the market. This constitutes one example of the absence of judicial deference in EU competition law, a claim progressively refuted by the Author throughout the book.

Concluding Part II of the book, the fifth chapter examines the work's last case-study: the substantive criterion against which mergers are assessed both under Regulation 4064/89 as well as under Regulation 139/2004. An analysis of the institutional context underpinning EU merger control 
starts by revealing, unsurprisingly, the virtual irrelevance of preliminary references in the interpretation of these instruments. Focusing on Phase II decisions that were eventually challenged, the Author comes to the conclusion that a considerable amount of these decisions were annulled for reasons relating to the application of the substantive criterion, with EU courts often reframing the Commission's approach. This was the case, for instance, in Tetra Laval/Sidel, where EU courts departed from the analytical framework originally proposed by the Commission for conglomerate mergers and annulled its decision, yet another example of meaningful judicial oversight over that administrative authority's interpretative choices.

Introducing Part III of the book, the sixth chapter, titled "The Shaping of EU Competition Law: Past and Prospects", explains the study's main findings, considering first the behaviour of the Commission and second that of the EU courts. From the three "analytical" chapters of the book, the Author extracts one main lesson regarding the decision-making practice of the Commission: this competition authority has consistently pursued the interpretation of EU competition law leading to the expansion of its powers. This is true for what is referred to as "one-shot interactions" as well as for "repeated interactions", the first meaning the crafting of legal tests and the second the engagement with the EU courts' case-law. Indeed, the Author's findings point in the sense that when crafting legal tests the Commission tends to design the scope of prima facie prohibitions in an unstructured and expansive manner, while opting for an expansive or narrow reading of the EU courts' rulings depending on their impact on the boundaries of its powers. This pattern of behaviour can be identified horizontally, across Articles 101 and 102 TFEU, as well as in merger control, and is consistent, for instance, with the Commission's reluctance in embracing economic analysis, what the Author describes as a type of "exogenous constraint" limiting the authority's freedom in defining its powers.

A changing institutional landscape creates new opportunities for the Commission's expansionist efforts, as an analysis of the introduction of commitment decisions seems to suggest. As the Author points out, this instrument allows for the Commission to deviate from established precedents as well as to design legal tests without being subject to any judicial counterweigh. This fosters the appearance of certain aberrations in substantive EU competition law as it is arguably the case of the ENI decision, where a firm's "strategic underinvestment" was qualified as an unlawful refusal to supply in contradiction with established case-law on this type 
of abuse of dominance. Indeed, from considering that a refusal to allow access to a given infrastructure may exceptionally be prohibited to finding that a refusal to invest in new capacity is equally unlawful goes quite an intellectual jump.

Another institutional mutation considered by the Author, the decentralisation in the application of Articles 101 and 102 TFEU, is found capable of shifting/consolidating the centre of gravity of judicial law-making on preliminary reference proceedings. In this context, the Commission's prerogative to make submissions to the Court may well become its main persuasive instrument before the Luxembourg judges. Because of this, it would be, in my opinion, desirable for the Court to reconsider its relatively restrictive stance on transparency in access to documents related to EU courts' proceedings, as established in Commission v. Breyer, in view of enabling an effective control over the Commission's behaviour. This effort was undertaken by the Author, who gaining access to the Commission's submissions in TeliaSonera reached the conclusion that, in that proceeding, the authority pleaded in favour of an interpretation of Article 102 TFEU, on the issue of "margin squeeze" practices, different from what it had established in soft law instruments. This type of conduct, in my view, hurts the Commission's legitimacy, revealing an incoherent administrative action close to arbitrariness.

Turning to the behaviour of the EU courts, the Author definitely refutes the curial deference discourse, progressively disproved throughout the book. Indeed, the figures examined in this study confirm a willingness of the EU courts both in effectively engaging with the analysis made by the Commission as well as in quashing this authority's decisions. There is, however, variation in EU courts' attitude towards the Commission's interpretation of the law, something explained by the path-dependant nature of the EU judiciary. Indeed, choices made early on, especially in the context of preliminary references, tend to be reiterated later in time. Variations in the case-law are more likely to be caused by the already mentioned "gravity effect" of the Commission's presence, essentially in annulment proceedings. EU courts show willingness to face existing substantive inconsistencies but on a case-by-case basis, without major "revolutions" in their case-law, something which does not come as a surprise considering how stability is valued in Luxembourg.

Chapter 7 concludes the book with the Author presenting some final thoughts on his research. On the issue of the substantive inconsistencies 
which have emerged in EU competition law, a conclusion is reached in the sense that these peculiarities are fuelled by the behaviour of an administrative authority, the Commission, often acting in view of expanding its powers, combined with varying intensities of judicial oversight over that authority's choices. Furthermore, the structure of EU competition law enforcement may, in some instances, aggravate these inconsistencies, as in the case of commitment decisions which, by design, are left unchecked by the EU judiciary. After setting "an agenda for future research", the Author concludes the book by reminding the reader that this work is also a study in administrative law, with some of its methods and teachings capable of being transposed into other contexts involving administrative action and administrative justice.

\section{Conclusion}

Consistency constitutes a (if not the) fundamental building block of legal certainty, a quality any legal system should strive to develop and preserve. A legal system such as the EU's competition law system, built on top of open-textured concepts, centred on an often opportunistic administrative authority, is, as demonstrated throughout this monograph, one under structural risks of developing substantive inconsistencies.

This book identifies these risks, calling the attention of the legal community to some very interesting tendencies in the institutional behaviour of the Commission and EU courts. It does so in an almost encyclopaedical style, covering the Author's view on virtually all main judicial and administrative landmarks of the field, in a "law in context" framework, producing innovative and much-needed insights for the discipline. 